\title{
Florfenicol induces early embryonic death in eggs collected from treated hens
}

\author{
S. AL-Shahrani and V. Naidoo*
}

\begin{abstract}
Background: Florfenicol, a commonly used veterinary antibiotic, was reported to have caused a severe drop in egg hatchability following its off-label use on a broiler breeder farm in South Africa. According to the pharmacovigilance report, hatchability dropped by $80 \%$ for up to a week following a five day course at $10 \mathrm{mg} / \mathrm{kg}$ (both males and females treated metaphylactically) to manage an Escherichia coli infection. While mammalian toxicity studies indicate the potential for early embryonic death in utero or testicular damage, no literature is available on the avian toxicity of florfenicol. For this study we investigated the effects of florfenicol at various doses from 10 to $90 \mathrm{mg} / \mathrm{kg}$ on the egg hatchability in a breeder flock we kept and established under controlled conditions, with the same cockerels and hens being exposed in a phased manner.

Results: Following five days of oral exposure, no toxic signs were evident in any of the cockerels or hens treated at doses up to $90 \mathrm{mg} / \mathrm{kg}$. Treatment of only the cockerels had no effect on egg hatchability, while treatment of only the hens at doses of 60 and $90 \mathrm{mg} / \mathrm{kg}$ resulted in decreased hatchability of $0 \%$ in comparison to $70 \%$ of the control as early $24 \mathrm{~h}$ after treatment. In all cases, decreased hatchability was associated with embryonic death at 5 days of development. The toxic effects of florfenicol were completely reversible with comparable hatchability being present by day 4 post-treatment withdrawal. Toxicity correlated with total egg florfenicol concentrations with an $L C_{50}$ of $1.07 \mu \mathrm{g} / \mathrm{g}$.

Conclusion: Florfenicol appears to be toxic to the developing chick embryo at around day 5 of incubation, in the absence of related toxicity in the hen or cockerel.
\end{abstract}

Keywords: Florfenicol, Broiler breeders, Chickens, Embryonic toxicity, Hatchability

\section{Background}

A spontaneous adverse reaction was reported to the Faculty of Veterinary Science, University of Pretoria, South Africa (reporter's details are kept confidential), describing an outbreak of Escherichia coli induced mortalities in a grandparent layer breeder flock in South Africa following the use of florfenicol. The report was according to South African legislation which supports the reporting of adverse reactions even when the arising through the use of non-registered and compounded medicines [1]. According to the spontaneous report, sensitivity testing showed florfenicol as the only drug with good efficacy. Florfenicol is a fluorinated derivative of cloramphenicol [2], with the chemical name 2,2-

\footnotetext{
*Correspondence: vinny.naidoo@up.ac.za

Department of Paraclinical Sciences, Faculty of Veterinary Science, University of Pretoria, Private Bag X04, Onderstepoort 0110, South Africa
}

dichloro-N-[1-(fluoromethyl)-2-hydroxy-2-[(methylsulfonyl) phenyl] ethyl] acetamide within the amphenicol group of antibiotics, with wide scale use in the treatment of pneumonia in food-producing animals [3]. In contrast to chloramphenicol which has been associated with the occurrence of aplastic anaemia in people, florfenicol does not contain the nitro group making it safe for use in food-producing animals [4]. Florfenicol is primarily bacteriostatic, with a range of activity against many Gramnegative and Gram-positive organisms, including certain chloramphenicol-resistant strains of Escherichia coli, Salmonella typhimurium and Staphylococcus aureus [5]. Florfenicol functions through the suppression of protein synthesis by inhibiting the peptidyl transferase enzyme as well as ribosomal translocation $[6,7]$.

While not registered for use in breeder fowls, the treating veterinarian made an informed decision to treat the birds with the non-registered florfenicol. The birds 
were subsequently treated with a compounded florfenicol formulation (active in glycerol), produced by a local pharmacy (Vtech compounding solutions), in the water at an equivalent dose of $10 \mathrm{mg} / \mathrm{kg}$ for 5 days. According to the spontaneous report the hens made a complete recovery with no further mortalities being recorded. A major side effect of reduced hatchability of $80 \%$ was reported, which lasted for a week from treatment initiation before returning to normal. Despite numerous attempts, further information was not forthcoming from the veterinarian or the farm in question.

While florfenicol is a described reproductive toxin this information has largely been obtained from classical mammalian laboratory toxicity tests. According to the summary material safety data sheet published by Schering-Plough [8], an oral two-generation reproductive study in rats (12 $\mathrm{mg} / \mathrm{kg} /$ day for 90 days) revealed reduced epididymal weights, decreased pup survival, and reduced milk production. Another two-generational teratogenicity study in mice, florfenicol $(40,120$, or $400 \mathrm{mg} / \mathrm{kg}$ by gavage) on days 6-15 of gestation showed signs of embryo lethality at the high dose. With an extensive literature review yielding no further information on the in vivo avian toxic potential of florfenicol, the aim of the following study was to establish the toxic effects of florfenicol on egg hatchability in a commercially representative breeding flock under controlled conditions.

\section{Methods}

\section{Animals}

Hyline hens were purchased from Eggspert eggs (Kempton Park, South Africa) and cockerels from HyLine SA (Midrand-South Africa) at the age of 15 weeks and already vaccinated for local conditions. The birds were individually marked with patagial tags prior to being randomly divided into four groups of 30 hens and 4 cockerels. The hen to cockerel ratio was at the recommended ratio of 8:1 for highest fertility within breeder flocks [9]. Birds were housed in large open pens of which the floors were covered with wood shavings in naturally ventilated rooms with curtained windows and had access to a standard diet fortified with salinomycin at $50 \mathrm{ppm}$ (Avi-Products Pty) and potable municipal water ad libitum. Research was approved by the Animal Use and Care Committee of the University of Pretoria (V070-08) and was conducted according the South Africa standards for the use of animals in research.

\section{Experimental design}

Florfenicol was supplied by Vtech Compounding Solutions Pharmacy (Midrand, South Africa) as the exact formulation (florfenicol in glycerol to a final concentration of $30 \mathrm{mg} / \mathrm{ml}$ ) reported in the spontaneous report. The study was completed in three phases with the same group of birds being used in all phases and a wash-out period of 3 weeks between phases. Treatments were administered once daily for 5 days by direct administration into the crop to ensure the correct exposure. In phase 1 , only the hens were treated at concentrations of 10,20 and $30 \mathrm{mg} / \mathrm{kg}$ or sterile water. In phase 2 , only the cockerels were treated with florfenicol at 30, 60, and $90 \mathrm{mg} / \mathrm{kg}$ or sterile water (Higher doses were selected due to the absence of toxicity in phase 1 ). In phase 3, only the hens were treated with florfenicol at 30, 60 and $90 \mathrm{mg} / \mathrm{kg}$ or sterile water. Prior to each phase the birds were all deemed to be clinically healthy, within normal weight limits, with all treatment groups having equivalent or better egg hatchability to the control.

\section{Monitoring of birds and chicks}

Hens and cockerels were evaluated daily for clinical signs of toxicity. Eggs were also collected on selected days for incubation (Buckeye egg incubator at 37 to $37.5{ }^{\circ} \mathrm{C}$ at $50 \%$ relative humidity, automatically turned hourly) to determine fertility by candling, egg break-outs or hatchings. A staggered pattern was adopted due to limited incubator space (Table 1). In total 30 eggs were incubated per time point for phase 1 and 2 and the majority of phase 3 (Tables 1, 2, 3). Fewer eggs were available for incubation in phase 3 due to a sequential termination of the adult hens for necropsy evaluation. Final egg evaluations by candling was undertaken on day 18. Eggs deemed infertile on candling were subjected to break-outs to determine time of embryonic death according to standard charts [10], while fertile eggs were taken to hatch. Fertility from the break-outs is presented as the percentage of eggs with viable foetuses (\% fertility). For eggs taken to hatch, chicks were evaluated for their

Table 1 Percentage fertility recorded during the study when only the hens were treated at the 10,20 or $30 \mathrm{mg} / \mathrm{kg}(n=30)$ and the method of evaluation

\begin{tabular}{lllllll}
\hline \multirow{2}{*}{ Time } & Event & \multicolumn{3}{c}{ Dose administered $(\mathrm{mg} / \mathrm{kg})$} & Method \\
\cline { 3 - 5 } & & 0 & 10 & 20 & 30 & \\
\hline-24 & Day before treatment & 88 & 93 & 87 & 77 & Hatch \\
24 & 24 h after 1'st Treatment & 89 & 78 & 76 & 76 & Break-out \\
72 & 24 h after third treatment & 74 & 70 & 73 & 61 & Hatch \\
96 & 24 h after 4'th treatment & 86 & 90 & 73 & 74 & Break-out \\
120 & Day 1 after withdrawal & 94 & 85 & 79 & 85 & Break-out \\
168 & Day 3 after withdrawal & 75 & 73 & 66 & 78 & Hatch \\
192 & Day 4 after withdrawal & 81 & 82 & 70 & 89 & Break-out \\
240 & Day 6 after withdrawal & 83 & 82 & 90 & 87 & Break-out \\
264 & Day 7 after withdrawal & 77 & 77 & 89 & 78 & Hatch
\end{tabular}

Time- indicates the time of eggs collection in relation to treatment. Methodindicates the methodology used to ascertain fertility for the specified time point. Values are presented as the percentage fertility of the total number of eggs incubated 
Table 2 Percentage fertility recorded during the study when only the cockerels were treated at the 30,60 or $90 \mathrm{mg} / \mathrm{kg}$ $(n=30)$ and the method of evaluation

\begin{tabular}{|c|c|c|c|c|c|c|}
\hline \multirow[t]{2}{*}{ Time } & \multirow[t]{2}{*}{ Event } & \multicolumn{4}{|c|}{ Dose administered $(\mathrm{mg} / \mathrm{kg})$} & \multirow[t]{2}{*}{ Method } \\
\hline & & 0 & 30 & 60 & 90 & \\
\hline-24 & Day before treatment & 81 & 72 & 71 & 67 & Hatch \\
\hline 24 & $24 \mathrm{~h}$ after 1'st Treatment & 92 & 92 & 88 & 92 & Break-out \\
\hline 72 & $24 \mathrm{~h}$ after third treatment & 75 & 92 & 73 & 76 & Hatch \\
\hline 96 & $24 \mathrm{~h}$ after $4^{\prime}$ th treatment & 87 & 86 & 83 & 77 & Break-out \\
\hline 120 & Day 1 after withdrawal & 70 & 77 & 83 & 83 & Break-out \\
\hline 168 & Day 3 after withdrawal & 70 & 65 & 62 & 77 & Hatch \\
\hline 192 & Day 4 after withdrawal & 87 & 92 & 87 & 87 & Break-out \\
\hline 240 & Day 6 after withdrawal & 86 & 90 & 93 & 92 & Break-out \\
\hline 264 & Day 7 after withdrawal & 63 & 77 & 63 & 57 & Hatch \\
\hline
\end{tabular}

Time- indicates the time of eggs collection in relation to treatment. Methodindicates the methodology used to ascertain fertility for the specified time point. Values are presented as the percentage fertility of the total number of eggs incubated

general quality; such as ability to stand, feather cover, shape of their beaks, movement ability and presence or absence of open navels. At the end of phase 3, hens in groups of five were sacrificed using $\mathrm{CO}_{2}$ at $0,1,2,3$ and 4 days post drug withdrawal for general necropsy evaluation.

\section{Florfenicol quantification in the egg}

In phase 3 , eggs collected on days 1 to 5 after treatment withdrawal were randomly collected from each group for quantification of their florfenicol concentrations using a modified method of Varma [3]. Eggs were cracked, shells

Table 3 Percentage fertility recorded during the study when only the hens were treated at the 30,60 or $90 \mathrm{mg} / \mathrm{kg}$ and the method of evaluation

\begin{tabular}{|c|c|c|c|c|c|c|c|}
\hline \multirow[t]{2}{*}{ Time } & \multirow[t]{2}{*}{ Event } & \multirow[t]{2}{*}{$\mathrm{n}$} & \multicolumn{4}{|c|}{$\begin{array}{l}\text { Dose administered } \\
(\mathrm{mg} / \mathrm{kg})\end{array}$} & \multirow[t]{2}{*}{ Method } \\
\hline & & & 0 & 30 & 60 & 90 & \\
\hline-24 & Day before treatment & 30 & 70 & 77 & 90 & 73 & Hatch \\
\hline 24 & $24 \mathrm{~h}$ after 1'st Treatment & 30 & 70 & 69 & 3 & 0 & Break-out \\
\hline 72 & $24 \mathrm{~h}$ after third treatment & 30 & 50 & 52 & 0 & 0 & Hatch \\
\hline 96 & $24 \mathrm{~h}$ after $4^{\prime}$ th treatment & 30 & 71 & 81 & 0 & 0 & Break-out \\
\hline 120 & Day 1 after withdrawal & 25 & 71 & 64 & 12 & 8 & Break-out \\
\hline 168 & Day 3 after withdrawal & 15 & 66 & 71 & 0 & 0 & Hatch \\
\hline 192 & Day 4 after withdrawal & 10 & 80 & 100 & 60 & 75 & Break-out \\
\hline 240 & Day 6 after withdrawal & 5 & 80 & 100 & 60 & 75 & Break-out \\
\hline 264 & Day 7 after withdrawal & 5 & 80 & 100 & 67 & 100 & Hatch \\
\hline
\end{tabular}

Time- indicates the time of eggs collection in relation to treatment. Methodindicates the methodology used to ascertain fertility for the specified time point. Values are presented as the percentage fertility of the total number of eggs incubated. From 120 h, five hens per days were slaughtered for necropsy evaluation discarded and the yolk/albumin homogenised. Two grams of egg homogenate in natural proportions were mixed with $100 \mu \mathrm{l}$ of $10 \mu \mathrm{g} / \mathrm{ml}$ thiamphenicol (internal standard) and $9 \mathrm{ml}$ ethyl acetate, vortexed and subsequently centrifuged at $2000 \times g$ for $15 \mathrm{~min}$. The resulting supernatant was decanted into a new tube, dried off for $30 \mathrm{~min}$ at $60{ }^{\circ} \mathrm{C}$ under a stream of nitrogen, prior to being mixed with $2 \mathrm{ml}$ high pure water (MilliQ) and $2 \mathrm{ml}$ hexane and re-centrifuged at $2000 \times g$ for $15 \mathrm{~min}$. For final extraction the supernatant was subjected to solid phase extraction (Varian BondElut C18) on cartridges primed with $4 \mathrm{ml}$ methanol, followed by $4 \mathrm{ml}$ MilliQ50 water. After the sample loading, a second wash was performed using $2 \mathrm{ml}$ MilliQ50 water after which the cartridge was allowed to dry under vacuum for $5 \mathrm{~min}$. Final elution was with $3 \mathrm{ml}$ methanol under vacuum for $5 \mathrm{~min}$. The eluent was dried under a stream of nitrogen for $30 \mathrm{~min}$ at $60{ }^{\circ} \mathrm{C}$, prior to being reconstituted in 500ul of $30 \%$ acetonitrile in reverse osmosis water (mobile phase) of which $100 \mu \mathrm{l}$ was injected onto the column [Phenomenex guard cartridges (AJO-4287) and LG reverse phase, Luna $5 \mu \mathrm{aC} 18$ (2); 100A; $150 \times 4.6 \mathrm{~mm}$ ] under isocratic flow of $1 \mathrm{ml} / \mathrm{min}$. Detection was via diode array on a Beckman HPLC at $223 \mathrm{~nm}$ (Fig. 1).

Results were interpreted against a fortified curve in which known concentrations of florfenicol and thiamphenicol were added to eggs collected from the control birds for which were maintained strictly florfenicol free for the entire study (Fig. 2). The method was linear from 0.1 to $10 \mu \mathrm{g} / \mathrm{g}$, with $0.1 \mu \mathrm{g} / \mathrm{ml}$ being the visual limit of the detection. The intra-day recovery $(n=2)$ was 91.96 and $103.02 \%$ for the lowest and highest concentration with a corresponding relative standard deviation (RSD) of 3.8 and $1.21 \%$ respectively. The inter-day recovery $(n=5)$ was 103.71 and $104.81 \%$ for the lowest and highest concentration, with the corresponding RSD being 9.23 and $5.56 \%$ respectively. All analysis was undertaken over a period of 5 days.

Florfenicol concentrations are presented for the different dose groups as mean and standard deviation. Egg concentrations were compared to the corresponding percentage fertility obtained by egg break-out. The florfenicol concentrations were plotted against percentage fertility on the natural logarithm scale to ascertain if a linear concentration versus response was present. The estimated concentration which could induce a $50 \%$ reduction in fertility (LC50 \%) was calculated from the best fit equation obtained by linear regression.

\section{Results}

For this study we investigated a pharmacovigilance report suggesting the reproductive toxic effect of florfenicol in a commercial breeding chicken flock. To obtain realistic results, we established breeding flocks with a hen to 


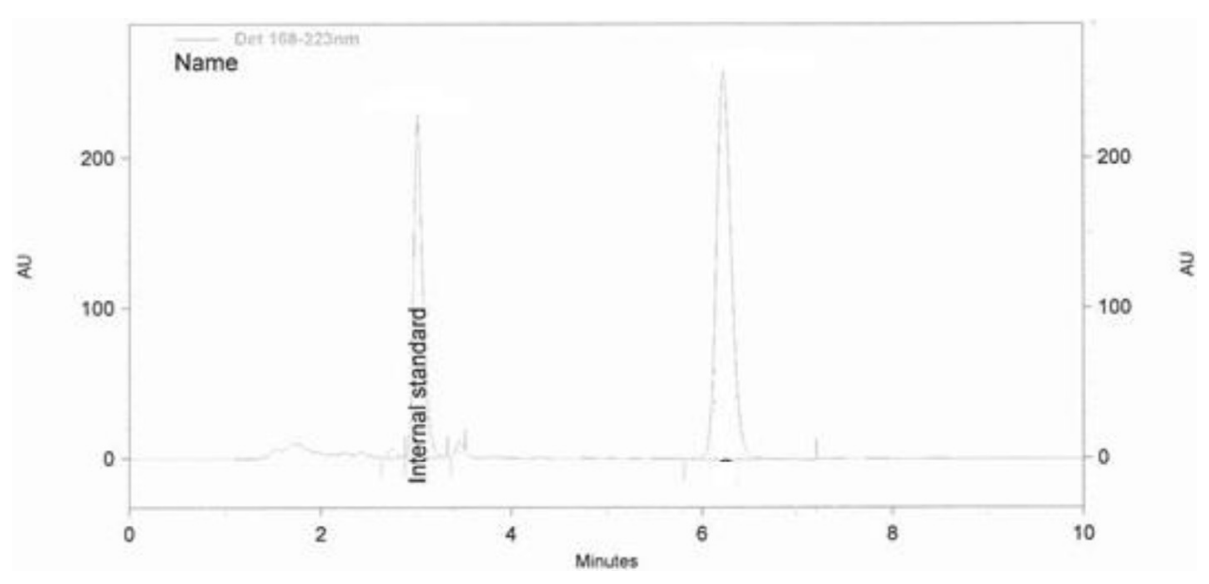

Fig. 1 Chromatogram for the $10 \mu \mathrm{g} / \mathrm{ml}$ sample, with the thiamphenicol internal standard

cockerel ratio of $8: 1$ as seen on commercial farms. To ascertain whether the effect was on the hens in the flocks, the cockerels in the flocks or just on eggs, the study was divided into three phases. For all three phase the same breeding birds were used. No clinical signs of toxicity were evident in any bird during the study.

The fertility of the flock was generally excellent and was above $70 \%$ at the start of each phase as determined by break-outs, and was comparable to the industry standard [11] with hatchability decreasing, as expected with the flock aging. Fertility as measured by hatchings were not as favourable as for the break-outs on certain days. However, since the fluctuations are a natural occurrence, the results for the treatment groups were always compared to the control group to rule out incidental environmental influences on hatchability.
In phase 1 (low dose hen) the only abnormality was a mild drop in fertility immediately after the fourth treatment of 72 and $74 \%$ for the 20 and $30 \mathrm{mg} / \mathrm{kg}$ groups respectively in comparison to $93 \%$ for the control group on break-outs (Table 1). This decrease corresponded with similar decrease in chicks hatching. No other time points in phase 1 showed signs of toxicity. In phase 2 (high dose males), no changes in fertility were observed for any of the groups $(n=30)$ with all groups showing similar $\%$ fertility to the control group (Table 2). No abnormalities were seen in any of the hatched chicks in phase 1 and 2.

In phase 3 , evidence of decreased fertility was present in both the 60 and $90 \mathrm{mg} / \mathrm{kg}$ groups (Table 3), with the day 18 percentage fertility being 3 and $0 \%$ respectively as early as $24 \mathrm{~h}$ after the first dose $(n=30)$. In contrast the control group had a percentage fertility of $70 \%$.

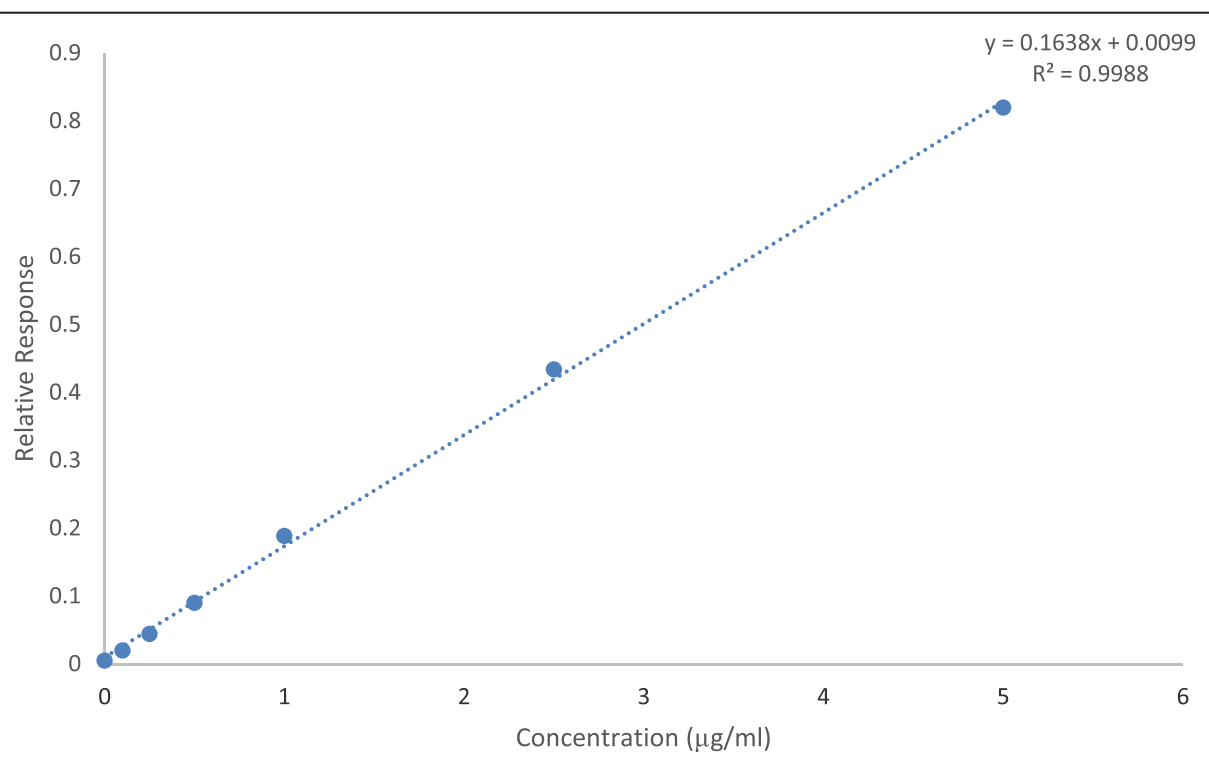

Fig. 2 Fortified standard curve for the various concentrations of florfenicol spiked into egg samples 
Fertility remained low until day 4 after treatment cessation $(n=5)$, with no chicks hatching from these treatment groups. Hereafter hatchability returned to control levels with no signs of abnormalities being present in hatching chicks. While none of the hens showed any signs of abnormalities on necropsy, egg breakouts showed that foetal deaths resulted at approximately day 5 of development.

Post-treatment egg concentration for the $90 \mathrm{mg} / \mathrm{kg}$ group was $4.27 \pm 0.76 \mu \mathrm{g} / \mathrm{g}$ on day 1 and had declined to $0.85 \pm 0.05 \mu \mathrm{g} / \mathrm{g}$ by day 5 post $-0 \mathrm{mg} / \mathrm{kg}$ treatment (Table 4). The depletion was not linear for all the groups with the 30 and $60 \mathrm{mg} / \mathrm{kg}$ group showing an increase in concentration from 24 to $48 \mathrm{~h}$, before starting to decline. When the percentage fertility was plotted against florfenicol egg concentrations, a linear relationship was present with linearity of $>85 \%$ (Fig. 3). The best fit equation was defined as $\mathrm{y}=-0.65 \mathrm{x}+4.61$, and an $\mathrm{LC}_{50}$ of $1.07 \mu \mathrm{g} / \mathrm{g}$.

\section{Discussion}

This is the first report of an adverse reaction associated with the use of florfenicol in breeding poultry that we are aware of, even though formulations of florfenicol are available for use in broilers internationally. For this study, we exposed an established breeder flock to florfenicol in controlled manner to ascertain if the drug could interfere with fertility as well as to determine if toxicity was at the level of the cockerel, hen and/or embryo. The reason for adopting this specific design came from the non-specific information provided in the spontaneous adverse drug report that related treatment to a subsequent decrease in fertility in a breeder flock. With the treatment being administered in the water and subsequent non-specific exposure of both the cockerels and hens, the resultant toxicity could have been from a direct toxic effect in either the cockerel or hen by interfering with their breeding potential. It is also possible that due to the drug's lipid solubility, it was distributed into either the albumin or yolk and subsequently was toxic to only the developing embryo.

In general florfenicol was not characterised by any overt signs of toxicity or pathological changes in the treated birds. For phase 1, in which the hens were treated at lower doses

Table 4 Concentration $(\mu \mathrm{g} / \mathrm{g})$ of florfenicol in the eggs $(n=5)$ at $24,48,72,96$ and $120 \mathrm{~h}$ after the withdrawal of treatment of florfenicol at 30, 60 or $90 \mathrm{mg} / \mathrm{kg}$ oid for 5 days

\begin{tabular}{llll}
\hline \multicolumn{2}{l}{ Time after dosing (hour) } & & Dose \\
\hline 24 & $30 \mathrm{mg} / \mathrm{kg}$ & $60 \mathrm{mg} / \mathrm{kg}$ & $90 \mathrm{mg} / \mathrm{kg}$ \\
48 & $0.68 \pm 0.05$ & $2.2 \pm 0.30$ & $4.27 \pm 0.76$ \\
72 & $1.08 \pm 0.11$ & $2.53 \pm 0.24$ & $3.8 \pm 0.34$ \\
96 & $0.59 \pm 0.02$ & $1.8 \pm 0.15$ & $1.85 \pm 0.28$ \\
120 & $0.39 \pm 0.06$ & $0.6 \pm 0.04$ & $1.12 \pm 0.13$ \\
\hline
\end{tabular}

of 10,20 and $30 \mathrm{mg} / \mathrm{kg}$ a moderate negative effect on fertility was seen at 20 and $30 \mathrm{mg} / \mathrm{kg}$ after four days of consecutive therapy. On egg break-out this was characterised by early embryonic death at approximately day 5 of development. When only the cockerels were treated in phase 2 , no changes in fertility were evident. For phase 3 , in which the hens were treated at the higher doses of 30,60 and $90 \mathrm{mg} /$ $\mathrm{kg}$ a major, albeit temporary, decrease in fertility characterised as a $100 \%$ decline was evident. As for phase 1, egg break-outs indicated that embryonic mortalities occurred at approximately day 5 of development with good correlation to total egg florfenicol concentrations.

With the absence of overt toxicity in either hens or cockerels, the failure of the product to interfere with cockerel fertility, and the presence of early embryonic death at day 5 , it would appear that florfenicol toxicity is limited to the developing embryo as a result of deposition of florfenicol within the egg prior to lay. The effect also appears to be absolute, as in the event that the embryo did not die, normal development to hatch resulted. The concentration response relationship in toxicity also provides a plausible link that the florfenicol was the cause of the embryonic death. This finding does differ to an in vitro toxicity study undertaken through the injection of florfenicol at 20 to $30 \mathrm{mg} / \mathrm{kg}$ egg weight, into day 4 embryonated eggs from Marandi breed chickens [12]. For the latter study no signs of toxicity was evident at necropsy on 18 day old embryos. While we are uncertain for the difference in sensitivity, breed differences may play a role. Another plausible reason could be the time of exposure, as in vivo exposure would result in the zygote being exposed to drug from the point of lay, while the older embryo may have reached a stage of non-susceptibility. As evident in this study, embryos that do survive florfenicol exposure do develop into normal healthy chicks.

What was also evident in the study was the slight difference in the time to maximum concentration (Cmax) within the eggs, with the $90 \mathrm{mg} / \mathrm{kg}$ group reaching $\mathrm{Cmax}$ at $24 \mathrm{~h}$ post-drug withdrawal and the 30 and $60 \mathrm{mg} / \mathrm{kg}$ dose reaching Cmax at $48 \mathrm{~h}$. This would suggest that the deposition of florfenicol into the egg is highly variable. This finding is not unusual and can be explained by pharmacokinetic theory which generally describes the deposition of drugs into the egg as being highly individually variable. The reasons for the latter is the need for the drug to distribute into the two media of the egg, namely the albumin and the yolk [13, 14], with the distribution being more rapid into the albumin reaching steady state usually by day 2-3 post-treatment, while steady state in the yolk can take up to 8 days. In the context of this study, the highly variable Cmax evident is explainable by both the variable nature of egg disposition as well as the study design which relied on eggs being randomly sampled per time point. Unfortunately in a natural open breeding 


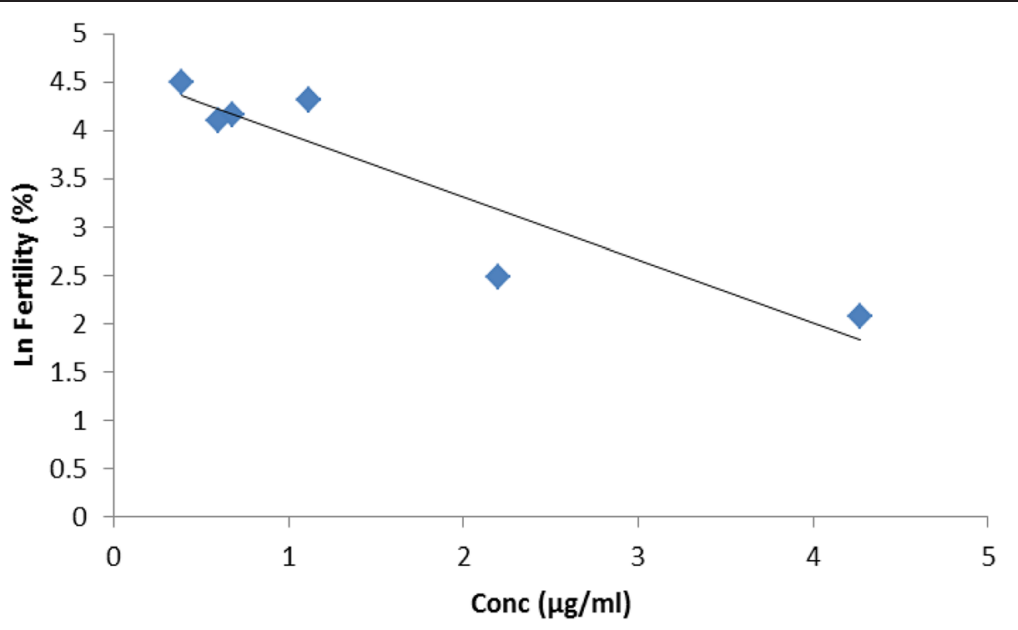

Fig. 3 Percentage fertility on the natural logarithmic scale obtained from egg break-out from the batch of eggs incubated (Table 3) versus corresponding egg florfenicol concentration $(n=5)$ from the separate batch of eggs assayed by HPLC

system in which the hens and cockerels are both housed on open floors, it is not possible to sequentially collect eggs from the same hen as their eggs are not identifiable.

Despite some previous evidence of embryotoxicity in the mouse, the mechanism of toxicity of florfenicol is yet to be described. Literature is however available for the other molecules in the amphenicol class. In a controlled murine study, 14- or 20-somite embryonic stages exposed to chloramphenicol (the progenitor compound of the amphenicol group), at concentrations of 0,200 , or $300 \mu \mathrm{g} / \mathrm{ml}$ for $22-24 \mathrm{~h}$ showed defects of the neural tube (failure to close) and the forebrain as well as the inhibition of haemoglobin formation [15]. The study was able to demonstrate that the toxic effect was due to inhibition of protein synthesis as a result of interference with the messenger RNA. In another study, chloramphenicol injected into turkey hatching eggs to eliminate Mycoplasma meleagridis at doses of 2.5 and $5 \mathrm{mg}$ also reduced hatchability, with embryo deaths being recorded before day 9 of the incubation period [16]. Finally in a rat model of teratogenicity it was found that the chloramphenicol interfered specifically with mitochondrial protein synthesis by decreasing the production of mitochondrial cytochrome oxidase enzyme (Cytochrome $C$ oxidase is the terminal enzyme in the electron transport chain located on the inner mitochondrial membrane) [17]. With florfenicol and chloramphenicol both sharing the same mechanism of protein synthesis inhibition, it is likely that florfenicol is toxic to the early stages of embryonic development via foetal protein synthesis inhibition.

Another important finding in this study was the lower susceptible of the study bird than that reported for the adverse drug reaction. While the reason for this difference is not known, it is possible that housing conditions, total days in lay, and the presence of the $E$. coli infections add to the general toxicity of the molecule. While it may be argued that the doses in use were excessively high and therefore unlikely to represent field adverse drug reactions, this is unlikely as the model is based on current regulatory best practice in evaluating drug toxicities. In the standard development of a veterinary medicine, it is a requirement for the drug to be tested at a control overdose (target species toxicity) at a minimum of $3 \mathrm{x}$ and $5 \mathrm{x}$ an overdose, with $10 \mathrm{x}$ overdose being the upper end of the scale [18]. The aim of these target species toxicity studies is to elucidate the toxic potential of a molecular in the target species as well to describe its likely adverse reaction from use i.e. these studies use a higher dose to elucidate likely side effects in a small sample size. For this study, birds exposed to a $3 \mathrm{x}$ to $9 \mathrm{x}$ overdose all showed signs of embryonic toxicity making it likely that this side effect would result under field conditions. Also important to note is that the non-South African recommended dose for the treatment of broiler chickens is $30 \mathrm{mg} / \mathrm{kg}$, the lowest identified toxic dose for this study [19].

An unexpected finding of this study was the absence of decreased egg fertility when only the cockerels were treated, as previous mammalian have indicated the ability for the drug to induce testicular toxicity. From Ando et al testicular toxicity seen in rats was characterized by vacuolated Sertoli cells was most likely as a result of reduced cytochrome activity [20]. With the cytochrome oxidases being important for aerobic sperm production, it would appear that avian Sertoli cells are less sensitive to the effects of the amphenicols. This also highlights that mammalian toxicity studies are not necessary indicative of toxicity in avian species. However, it must be noted that this study was designed to investigate the effects of florfenicol on cockerel breeding potential under commercial conditions at a ratio one cockerel to eight 
hens, with the result that this study design may not have been sensitive enough to elucidate more insidious testicular/epididymal toxicity. As a result, it would still be important to evaluate the direct effect of florfenicol in a larger group of breeding-aged cockerels, for further sex-related side effects.

\section{Conclusion}

We conclude that florfenicol has the potential to induce early embryonal death in chickens. We would recommend that the drug be avoided in breeding birds, unless the value of the breeder flock dictates that the health of the flock and return to productivity is more important than resultant decrease in egg fertility.

\section{Competing interests}

None of the authors has any financial or personal relationships that could inappropriately influence or bias the content of the paper.

\footnotetext{
Authors' contribution

VN: Conceptualised the study, assisted with the animal phases, participated in drafting the manuscript, and served as degree supervisor for SA; SA: Undertook the research, assisted with the egg analysis, and participated in drafting the manuscript. Both authors read and approved the final manuscript.
}

\section{Acknowledgements}

The authors wish to thank Mrs. MSG Mulders who undertook the HPLC analysis for this project. This project was funded by the Saudi Food and Drug Authority as part of an MSc student project.

Received: 24 February 2015 Accepted: 6 August 2015

Published online: 18 August 2015

\section{References}

1. Naidoo V, Gehring R. Overview of suspected adverse reactions to veterinary medicinal products reported in South Africa (March 2001-February 2002). J S Afr Vet Assoc. 2002;73:227-9.

2. Budavari S. The Merck Index. An Encyclopaedia of Chemicals, Drugs, and Biologicals. 12th ed. New Jersey: Merck Research Laboratories; 1996. p. 41-6.

3. Varma KJ. Microbiology, pharmacokinetic disposition and safety of florfenicol in cattle. In: Proceedings of the XVIII World Buiatrics Congress. Italy: Bologna; 1994. p. 18-24.

4. Yunis AA. Chloramphenicol: relation of structure to activity and toxicity. Annu Rev Pharmacol Toxicol. 1988;28:83-100.

5. Syriopoulou VP, Harding AL, Goldmann DA, Smith AL. In vitro antibacterial activity of fluorinated analogs of chloramphenicol and thiamphenicol. Antimicrob Agents Chemother. 1981;19:294-7.

6. Sams RA. Florfenicol: chemistry and metabolism of a novel broad-spectrum antibiotic. In: Proceedings of the XVIII World Buiatrics Congress. Italy: Bologna; 1994. p. 13-7.

7. Cannon M, Harford S, Davies J. A comparative study on the inhibitory actions of chloramphenicol, thiamphenicol and some fluorinated derivatives. J Antimicrob Chemother. 1990;26:307-17.

8. Schering-Plough. Material Safety Data Sheet, Florfenicol Powders. 2004 http://www.fws.gov/fisheries/aadap/03_Florfenicol/06_MSDSs/MSDS\%2010697_Florfenicol.pdf. Accessed Jan 2015.

9. Al-Rawi B. Sex ratio effects on egg production. Poult Sci. 1980;59:1546-7.

10. Hyline: Technical Library - Weekly Performance Standards. 2012. http://www.hyline.com/userdocs/pages/PERF_STDS_2-12-15.pdf. Accessed May 2015.

11. Embryonic development of young chicks. 2007. http://www.strombergschickens com/fullsize/895/88. Accessed Jan 2014.

12. Tavakkoli H, Derakhshanfar A, Noori GS. The effect of florfenicol egginjection on embryonated chicken egg. IJABBR. 2014;2:496-503.

13. Kan CA, Petz M. Residues of veterinary drugs in eggs and their distribution between yolk and white. J Agric Food Chem. 2000;48:6397-403.
14. Hekman P, Schefferlie GJ. Kinetic modelling and residue depletion of drugs in eggs. Br Poult Sci. 2011;52:376-80.

15. Billett FS, Collini R, Hamilton L. The effects of $D$ - and L-threo-chloramphenicol on the early development of the chick embryo. J Embryol Exp Morphol. 1965;13:341-56.

16. McCapes R, Yamamoto R, Ortmayer H, Scott W. Injecting antibiotics into turkey hatching eggs to eliminate Mycoplasma meleagridis infection. Avian Dis. 1975;19:506-14.

17. Bass L, Liebert CA, Lee MD, Summers AO, White DG, Thayer SG, et al. Incidence and characterization of integrons, genetic elements mediating multiple-drug resistance, in avian Escherichia coli. Antimicrob Agents Chemother. 1999:43:2925-9.

18. VICH. Target Animal Safety for Veterinary Pharmaceutical Products. 2008. http://www.vichsec.org/component/attachments/attachments/ 310.html?task=download. Accessed May 2015.

19. Khalil $\mathrm{S}$, Hamed $\mathrm{E}$, Hassanin O. Residue withdrawal of florfenicol from the serum and edible tissues of broiler chickens. J Am Sci. 2012;8:514-24.

20. Ando J, Ishihara R, Imai S, Takano S, Kitamura T, Takahashi M, et al. Thirteen-week subchronic toxicity study of thiamphenicol in F344 rats. Toxicol Lett. 1997;91:137-46.

\section{Submit your next manuscript to BioMed Central and take full advantage of:}

- Convenient online submission

- Thorough peer review

- No space constraints or color figure charges

- Immediate publication on acceptance

- Inclusion in PubMed, CAS, Scopus and Google Scholar

- Research which is freely available for redistribution 